\title{
A posição do psicanalista em um espaço de acolhimento para pequenas crianças e seus pais: da sustentação simbólica à constituição subjetiva*1
}

\author{
The position of psychoanalysts in a welcoming \\ place for young children and their parents: from \\ symbolic support to subjective constitution
}

\author{
Ana Francisca Lunardelli-Jacintho*2 \\ Maria Cristina Machado Kupfer*3 \\ Alain Vanier*4
}

Partindo de um questionamento sobre as especificidades da clínica psicanalítica com bebês, o presente artigo discute a posição do psicanalista em um espaço de acolhimento para crianças pequenas e seus pais. Conclui que ele opera pela sustentação simbólica da função materna e propõe uma torção no que concerne à noção de prevenção, concebendo-a como o acompanhamento que participa da instauração do processo de constituição psíquica do bebê.

Palavras-chave: Psicanálise com bebês, espaço de acolhimento, posição do psicanalista, constituição psíquica

*1 Artigo baseado na Tese de Doutorado em Psychopathologie et Psychanalyse/Psicologia realizada na Université Paris 7 - Diderot em cotutela com a Universidade de São Paulo (USP) e intitulada Rencontres pulsionnelles et constitution du sujet dans un lieu d'accueil enfants-parents: les possibles de la prévention précoce (Encontros pulsionais e constituição do sujeito em um espaço de acolhimento para crianças e pais: os possíveis da prevenção precoce), 2015.

*2 Associação PREAUT (Paris, França).

*3 Universidade de São Paulo - USP (São Paulo, SP, Br).

*4 Université Paris 7 - Diderot (Paris, França). 


\section{Como o bebê questiona a psicanálise?}

A clínica psicanalítica com bebês reatualiza importantes temas de debates colocados desde os primórdios da psicanálise, tais como a oposição entre a criança e o infantil (Lajonquière, 2006) e o estatuto da observação direta como possível via de acesso a este último (Vanier, 2011). Além disso, a questão de uma profilaxia de neuroses por meio da educação, proposta inicialmente por Freud (1907/1976), mas abandonada mais tarde (1933/2004), também reaparece nessa clínica.

Atualmente diversos estudos pretendem identificar sinais precoces de risco psíquico relacionados a patologias como o autismo. Numa perspectiva psicanalítica, tais sinais correspondem aos efeitos indiretos da instalação da subjetividade, e informam sobre o curso tomado pelo processo de constituição psíquica (Kupfer, 2003). Podem, ainda, ser considerados como sintomas, na medida em que necessitam uma interpretação para além da observação direta (Bernardino, 2008). Assim, o analista opera uma leitura das inscrições produzidas no bebê pelo Outro e da forma como este responde com seu corpo (Jerusalinsky, 2008). Nesse sentido, o sintoma presente na organização corporal e nas produções do bebê pode ser considerado um dado a ver a ser decifrado e articulado à escuta do discurso parental.

Também central nessa clínica é a questão do tempo precoce da intervenção. Com efeito, por localizar-se em um momento dito inicial do nascimento psíquico do sujeito, questiona a relação entre o tempo sincrônico da estrutura, submetido à ordem da linguagem e do desejo, e os elementos diacrônicos do real do organismo, 


\section{ARTIGOS}

tais como o crescimento e a maturação (Jerusalinsky, 2002). O tempo lógico do inconsciente é caracterizado por Freud (1918/2009) pela atemporalidade do infantil e pela retroação subjetiva (après-coup), distinguindo-se do tempo cronológico linear, na medida em que é determinado por um evento posterior que opera atribuindo um novo sentido ao primeiro. Desse modo, a condição de "inacabamento da infância" (Bernardino, 2004) torna impossível qualquer tentativa de previsão sobre o que o sujeito fará com o que viveu em sua primeira infância. A esse propósito, Ansermet (2008) defende a brecha temporal entre o passado e o futuro de que fala Arendt (2007), como espaço de abertura à liberdade do sujeito e que impede qualquer predição. Trata-se de uma importante indicação, segundo a qual o campo da prevenção deve operar no sentido de abertura a esse intervalo, a partir do qual o sujeito advém.

Novas questões emergem ainda: como considerar a dimensão do impossível presente no fato de escutar os que não falam, e como se posicionar diante daqueles cujo psiquismo está em vias de constituição, introduzindo inevitavelmente a questão da presença dos pais nas intervenções? Partindo dessas interrogações, o presente artigo visa discutir a posição do psicanalista no tratamento com bebês e, mais especificamente, no contexto do espaço de acolhimento situado no campo da prevenção.

\section{Especificidades da clínica com bebês e a posição do psicanalista}

Para Bernardino (2008), o analista intervém quando os pais se encontram impedidos de ocupar o lugar do Outro para o bebê, devido às falhas ou vacilações de seu saber inconsciente. O primeiro oferece, então, ao bebê, o encontro com um "bom entendedor" cuja escuta lhe permite reencontrar o Outro perdido. Ainda segundo a autora, na vertente imaginária dessa clínica, quando o agente materno está impossibilitado de falicizar o bebê, a intervenção do analista visa colocá-lo no lugar do falo, deixando-se maravilhar por ele e permitindo à mãe identificar-se com esse olhar. No registro simbólico, como mediador da Lei e da cultura, opera um corte mediante os efeitos de linguagem de suas intervenções. Além disso, ao incidir sobre a relação do bebê com seus pais, produz como efeito a absorção de suas angústias e a consequente liberação da criança. $\mathrm{O}$ analista ocuparia, enfim, uma função de terceiro para a família, ligada à função paterna, e que a autora caracteriza como apaziguadora por conferir um lugar ao sujeito. Desse modo, o efeito de suas intervenções seria dado a ver no corpo da criança, muitas vezes de forma espetacular, como um sinal de que o 
bebê teve acesso às intervenções. No entanto, para além do desaparecimento dos sintomas, o objetivo do trabalho é que o bebê possa manifestar sinais de presença e de interesse pelo mundo, capacidade de brincar e receptividade às palavras.

A esse propósito, Jerusalinsky (2008) avança que o analista deve operar sustentando os pais no exercício das funções materna e paterna e emprestando significantes ao bebê. Considera que as intervenções podem ter "efeitos constituintes para o bebê" (p. 40), graças à sua permeabilidade às inscrições. Portanto, de acordo com essa autora, em diferentes momentos do tratamento o analista deve poder supor a criança como sujeito, reconhecer e nomear suas produções. Opera, assim, por vezes, o lugar do Outro que produz marcas no bebê graças à transferência dos pais sobre ele. Desse modo, a direção do tratamento será diferente em função de tratar-se do sofrimento dos pais ligado ao bebê fantasmático ou de um obstáculo da própria criança na sua constituição subjetiva.

$\mathrm{O}$ fantasma materno representa, para alguns autores, um limite às intervenções na clínica psicanalítica com bebês. Teperman (2005) ressalta a impossibilidade de incidir sobre ele e sugere que o trabalho teria como objetivo contornar o fantasma para liberar um outro lugar para a criança. Para Kupfer e Lajonquière (2014), na clínica com crianças autistas em instituições, trata-se de operar sobre o discurso dos pais e não sobre seus fantasmas. Assim, a escuta psicanalítica corresponderia, mais precisamente, à promoção de deslocamentos relativos à posição subjetiva dos pais na sua relação com a criança. A intervenção nessa clínica atuaria, em particular, sobre o laço em que a criança está inserida, ou seja, sobre a posição dos pais em relação ao bebê, e sua posição diante do Outro. Tal concepção do laço diferencia-se radicalmente da noção de díade mãe-bebê e permite pensar as funções materna e paterna para além das pessoas dos pais.

Em relação ao lugar ocupado pelo analista, Neves e Vorcaro (2010) questionam se, no tratamento com bebês, ele poderia operar como agente materno, como "suplente do Outro primordial não instalado" (p. 100) capaz de localizar um sujeito. Defendendo essa posição, Cullere-Crespin (2007) avança que o analista pode vir habitar "o lugar do Outro faltante, portador de um desejo" (p. 66) ${ }^{1}$ para a criança. Laznik (1995/2003), por sua vez, afirma que o analista, no lugar do Outro, estaria disposto a "doar sua falta" para que o desejo possa surgir.

${ }^{1}$ Os textos originalmente em francês foram traduzidos livremente pelos autores. 


\section{ARTIGOS}

$\mathrm{O}$ atendimento de bebês é ainda situado, por alguns, no campo da prevenção, pois realiza-se diante da não instauração ou de falhas no laço do bebê com o Outro, permitindo a retomada da constituição subjetiva da criança (Laznik, 1996/2004) e o estabelecimento inicial ou o restabelecimento do laço com os pais (Bernardino, 2008). Desse modo, tornaria possível a instauração até então impedida de estruturas psíquicas, em que o circuito pulsional da criança aparece como um aspecto central. A prevenção é assim concebida como a antecipação do sujeito no bebê (Teperman, 2005), ou como oferta visando permitir que a criança adquira as "condições estruturais" mínimas necessárias à sua constituição subjetiva, tal como proposto por Mariotto (2009) nas creches. Nessas, Bernardino (2014) defende, nos casos excepcionais em que o bebê apresenta sinais de risco para sua constituição psíquica, um possível "papel preventivo" do professor que, sustentado pelo psicanalista em posição de terceiro, poderia comparecer com seu desejo e facilitar a retomada do processo pulsional na instalação da subjetividade do bebê. Essa proposta de ampliação da clínica psicanalítica com bebês é de grande importância, já que aponta para uma intervenção possível no espaço da creche, de forma análoga àquela defendida por diversos autores no contexto do atendimento terapêutico individual.

No que diz respeito ao espaço de acolhimento, qual é a posição do psicanalista? Ocuparia também aí o lugar do Outro Primordial para a criança? Operaria no campo da prevenção?

\section{O espaço de acolhimento para pequenas crianças e seus pais}

Inspirados no modelo da Maison Verte (Casa Verde) fundada por Françoise Dolto, diversos espaços de acolhimento foram criados na França nas últimas décadas. O presente artigo resulta do trabalho clínico do îlotBébés, ${ }^{2}$ que recebe crianças de até três anos acompanhadas de um adulto. Informal, gratuito e anônimo, o dispositivo oferece um espaço livre e voltado ao brincar, sempre na presença de psicólogos de orientação psicanalítica. Nele não há atendimentos individuais e não é necessário que os pais apresentem explicitamente qualquer demanda.

${ }^{2}$ Fundado em 2006 pelo dr. Bruno Rebillaud e situado no $13^{\circ}$ arrondissement de Paris. 
No que diz respeito à Maison Verte, Dolto (1977/2009a) afirma que o papel inicial dessa estrutura, além da socialização das crianças e da escuta dos pais, seria o de favorecer a prevenção por meio de uma intervenção precoce. A psicanalista defende, assim, que a verbalização promovida nesse espaço teria incidências sobre as diversas dificuldades apresentadas pelas pequenas crianças, mas a noção de prevenção é utilizada de forma não específica pela autora, referindo-se aos transtornos das crianças, às angústias dos pais e à neurose de uma forma geral (Dolto, 1980/2009b).

Publicações mais recentes de psicanalistas que atuam nesse tipo de dispositivo defendem que a prevenção não corresponderia à eliminação do sintoma, mas ao efeito produzido pela "mensagem inaudível" da criança (Olivier, 2013) e pelo apaziguamento da angústia dos pais (Rouvray, 2013). Em trabalho anterior interrogamos a noção de prevenção em um espaço de acolhimento a partir da questão do olhar sobre o corpo do bebê (Jacintho, 2012). Sublinhamos as derivas sofridas, na atualidade, pela noção de prevenção que, baseada no discurso médico, encontra-se submetida à tendência preditiva de certas políticas públicas de saúde mental infantil, como, por exemplo, na França. Concebemos, por fim, a prevenção como a possibilidade de acompanhar a constituição psíquica do sujeito no seu laço com o Outro. Dando continuidade à nossa reflexão acerca desse trabalho de acompanhamento e seus efeitos sobre o bebê e sua família, buscamos em seguida interrogar nossas intervenções nesse espaço (Lunardelli-Jacintho, 2015). A partir de uma situação clínica trataremos, a seguir, da posição ocupada pelo psicanalista nesse dispositivo, para então apresentar nossa concepção de prevenção.

\section{Sonia e sua mãe}

Sonia tem nove meses quando vem ao espaço de acolhimento com sua mãe, seguindo os conselhos do pediatra. Após colocar sua filha deitada no tapete de bebês, discorre longamente sobre as dificuldades em torno do nascimento de Sonia e de um acidente ocorrido na maternidade: quando estava internada no serviço de neonatalogia, devido a complicações no parto, um enfermeiro teria deixado uma perfusão ao lado do pé de sua filha, que sofreu queimaduras e teve que passar por procedimento cirúrgico. A mãe nos mostra suas cicatrizes, afirma que deseja processar o hospital e exprime suas inquietações sobre o futuro de Sonia: terá dificuldades para andar? Enquanto isso, Sonia brinca com um chocalho que encontra sobre o tapete e realiza 


\section{ARTIGOS}

movimentos de descarga motora e de hiperextensão das pernas e braços. Mostra-se também interessada pelos adultos e crianças em sua volta.

$\mathrm{Na}$ vez seguinte, a mãe posiciona Sonia sentada, com várias almofadas atrás dela para que fique nessa posição. Esvazia, então, na sua frente, um recipiente contendo muitos brinquedos para bebês. Sonia fica completamente rodeada de almofadas e brinquedos e não tem espaço para se movimentar. Solta alguns gritos e vocaliza muito, parecendo bastante tensa em seu corpo rígido, o que nomeamos. A mãe pede para ficarmos com sua filha enquanto vai ao banheiro. Esta a acompanha com os olhos, mas quando sua mãe volta, afirma que Sonia "não está nem aí" (sic) para ela. Constatamos, assim, que as projeções imaginárias dessa mãe participam da dificuldade, que nos dá a ver, em interpretar as manifestações corporais de sua filha.

Nas próximas vezes, a mãe instala Sonia novamente entre almofadas e brinquedos, apesar de nossas sugestões para que a coloque em outra posição. Nos interpela dizendo que fica muito "incomodada" com o fato de que sua filha "grita o tempo todo" (sic). Isso ocorreria em momentos pouco específicos, não apenas quando procura chamar sua mãe. O pediatra teria the dito que é uma forma de se expressar, mas a mãe insiste que "não entende" (sic) e quer nos mostrar como ela grita. Dirigimo-nos a Sonia dizendo-lhe que é muito difícil para sua mãe não poder entender o que ela está pedindo e que percebemos que tem muito a dizer. Sonia escuta com atenção e sua mãe começa, então, a relatar situações em que os gritos de sua filha a incomodaram, como, por exemplo, no dia em que ela e o marido a levaram para uma reunião de trabalho da empresa. Questionada sobre a presença de sua filha numa situação de trabalho, pode enfim começar a exprimir sua dificuldade em ficar em casa cuidando de Sonia, já que trabalhava muito e sente muita falta disso. Desenvolve, por fim, uma narrativa em torno de seu cansaço, presente desde o nascimento de seu bebê, assunto que retoma outras vezes.

Essa mãe expressa, assim, num primeiro momento, sua incompreensão como dificuldade em construir uma hipótese sobre o que manifesta sua filha. Sonia apresenta-se como um bebê muito vivo, mas bastante tenso em seu corpo. Agita-se muito e grita com frequência, o que entendemos como uma tentativa de apelo. Por outro lado, a dimensão do bebê fantasmático, que não "está nem aí" para sua mãe, que só sabe gritar e que a impede de trabalhar, parece ocupar todo o seu espaço psíquico e dificulta a presença do prazer compartilhado na relação. Com efeito, apesar de poder brincar sozinha e aceitar que participemos de suas brincadeiras, Sonia não solicita sua mãe, e esta também não procura iniciar trocas com ela. 
$\mathrm{Na}$ medida em que pode falar de sua dificuldade em saber o que Sonia quer e de como a deixa cansada, uma abertura se produz. Assim, enquanto a observamos e comentamos seus gestos, a mãe começa a olhar sua filha brincar e compartilhar suas alegrias e pesares, como no dia em que propomos colocá-la deitada sobre o tapete e que Sonia começa a tentar engatinhar. Conta que, em casa, Sonia passa muito tempo no bebê conforto e levanta a hipótese de que talvez seja por isso que ela grite tanto. Aos poucos, momentos de encontros em torno do brincar se tornam possíveis, e os gritos de Sonia desaparecem, dando lugar às primeiras palavras. Dessa forma, ao reconhecermos as produções de Sonia como uma mensagem e ao sustentarmos a função materna de atribuição e suposição do sujeito, favorecemos a presença de seu olhar desejante. Como pensar a posição que ocupamos nesse trabalho de acompanhamento a partir de nossas intervenções?

\section{A posição do psicanalista no espaço de acolhimento: sustentar a função materna e favorecer a instauração da subjetividade do bebê}

Tal como indicamos, diversos autores defendem que o analista pode ocupar, no tratamento com bebês, o lugar do Outro primordial. A partir de nosso trabalho, propomos que o psicanalista se situa, por vezes, no lugar do Outro para a criança, mas também para os pais. Desse modo, se ele é, continuamente, levado a intervir a partir da verbalização e da nomeação do dado a ver do corpo da criança, isto não visaria somente a produção direta de marcas sobre a primeira - o que, aliás, só corresponderia a casos excepcionais - mas, principalmente, a tornar possível ao agente materno retomar para si sua função atributiva, responsável por introduzir a criança na linguagem. Portanto, não se trata de ocupar o lugar do Outro para a criança no lugar da mãe, ${ }^{3}$ mas de intervir para permitir que ela mesma possa (re)assumir esse lugar, na medida em que isso seja possível para ambos. Situamo-nos, então, mais especificamente, na posição de Outro do Outro para o bebê, a partir da qual ocupamos uma posição de terceiro para ambos e sustentamos a função materna.

Assim, o acompanhamento oferecido é, primeiramente, de ordem narcísica, mas visa também o surgimento do investimento libidinal materno, permitindo à criança ocupar o lugar de objeto de desejo e, à mãe, exercer

${ }^{3}$ Ao mencionarmos a mãe, nos referimos ao agente que exerce a função materna. 


\section{ARTIGOS}

sua função de antecipação e de suposição do sujeito. Tal sustentação simbólica possibilita, com efeito, reposicionar a dimensão significante no centro do laço, para que o sujeito possa ser suposto, mas também reconhecido na sua parte de enigma e, posteriormente, como separado do Outro. Essa função tem como efeito favorecer o processo de alienação da criança ao desejo do Outro e suas tentativas de fisgar o gozo materno. O dispositivo favorece, portanto, a entrada do bebê no mundo simbólico ao intervir em casos de dificuldades no estabelecimento inicial do laço que podem provir do bebê, mas também da impossibilidade materna em obter satisfação nos cuidados ministrados.

A partir de nossa prática, propomos uma torção no que concerne à noção de prevenção. Contrapondo-nos à ideia de que a prevenção se define como procura de impedir o surgimento de sintomas ou do sofrimento, defendemos que se trata, precisamente, de criar condições para a instauração das estruturas psíquicas do bebê. Ao sustentar o estabelecimento do laço com o Outro em suas dimensões pulsional e narcísica, mas, também, ao propiciar a separação necessária entre eles, essa clínica opera no sentido de favorecer a constituição psíquica do bebê. Trata-se, assim, de um acompanhamento que pode ser considerado estruturante, na medida em que permite à criança ocupar o lugar de sujeito do desejo no laço com o Outro.

\section{Referências}

Ansermet, F. (2008). Prédire le devenir. Vacarme, 45, 75-78.

Arendt, H. (2007). La crise de la culture. Paris: Folio Essais.

Bernardino, L. M. F. (2004). As psicoses não-decididas da infância: um estudo psicanalítico. São Paulo, SP: Casa do Psicólogo.

Bernardino, L. M. F. (2008). É possível uma clínica psicanalítica com bebês? In M. C. M. Kupfer, \& D. Teperman (Orgs.), O que os bebês provocam nos psicanalistas? São Paulo, SP: Escuta.

Bernardino L. M. F. (2014). A creche, o professor e o desejo. Documento não publicado. Congresso LEPSI IP/FE-USP 2014.

Cullere-Crespin, G. (2007). L'épopée symbolique du nouveau-né: De la rencontre primordiale aux signes de souffrance précoce. Paris: Éditions érès.

Dolto, F. (2009a). Projet de Centre de l'enfance. In Une psychanalyste dans la cité: L'aventure de la Maison Verte. Paris: Gallimard. (Trabalho original publicado em 1977). 
Dolto, (2009b). La Maison Verte: Un lieu de rencontre et de loisirs pour les toutpetits avec leurs parents. In Une psychanalyste dans la cité: L'aventure de la Maison Verte. Paris: Gallimard. (Trabalho original publicado em 1980).

Freud, S. (1976). Séance du 18/12/1907. In Les premiers psychanalystes: Minutes de la Société psychanalytique de Vienne (Tome I: 1906-1908). Paris: Gallimard. (Trabalho original publicado em 1907).

Freud, S. (2004). Nouvelle suite des leçons d'introduction à la psychanalyse. XXXIVe Leçon: Éclaircissements, applications, orientations. In Euvres complètes, Psychanalyse (Vol. XIX, 1931-1936). Paris: PUF. (Trabalho original publicado em 1933).

Freud, S. (2009). L'homme aux loups. Paris: PUF/Quadrige. (Trabalho original publicado em 1918).

Jacintho, A. L. (2012, dez). Clínica da prevenção: o olhar sobre o corpo do bebê. Estilos da Clínica, 17(2), 242-261.

Jerusalinsky, A. N. (2002). O nascimento do ser falante. In L. M. F. Bernardino, \& C. M. Fernandes (Orgs.), O bebê e a modernidade: abordagens teórico-clínicas. São Paulo, SP: Casa do Psicólogo.

Jerusalinsky, J. (2008). Clínica interdisciplinar com bebês: qual a importância clínica de considerar a especificidade desse campo? In M. Wanjntal (Org.), Clínica com crianças: enlaces e desenlaces. São Paulo, SP: Casa do Psicólogo.

Kupfer, M. C. M. (2003, junho). Pesquisa multicêntrica de indicadores clínicos de risco para o desenvolvimento infantil. Revista Latinoamericana de Psicopatologia Fundamental, VI(2), 7-25.

Kupfer, M. C. M., \& Lajonquière, L. (2014). Quelle place pour les parents d'enfants autistes dans le soin? Le dispositif Lugar de Vida au Brésil. Dialogue, 206, 11-22.

Lajonquière, L. (2006, jan-jun). A psicanálise e o debate sobre o desaparecimento da infância. Educação \& Realidade, 31(1), 89-106.

Laznik, M.-C. (2003). Vers la parole. Trois enfants autistes en psychanalyse. Paris: Denoël. (Trabalho original publicado em 1995).

Laznik, M.-C. (2004). Poderíamos pensar na prevenção da síndrome autística? In D. B. Wanderley (Org.). Palavras em torno do berço. Salvador, BA: Ágalma, Coleção de Calças Curtas. (Original publicado em 1996).

Lunardelli-Jacintho, A. F. (2015). Rencontres pulsionnelles et constitution du sujet dans un lieu d'accueil enfants-parents: les possibles de la prévention précoce. Tese de doutorado em Psychopathologie et Psychanalyse/Psicologia. Université Paris 7 - Diderot e Universidade de São Paulo (cotutela internacional). $427 \mathrm{p}$.

Mariotto, R. M. M. (2009). Cuidar, educar e prevenir: as funções da creche na subjetivação de bebês. São Paulo, SP: Escuta. 


\section{ARTIGOS}

Neves, B., \& Vorcaro, A. (2010). O tratamento do infans em situação de grave patologia por um "outro acolhedor": o lugar da intervenção do psicanalista na clínica com bebês. In D. C. Barbosa, \& E. Parlato-Oliveira (Orgs.), Psicanálise e clínica com bebês: sintoma, tratamento e interdisciplina na primeira infância. São Paulo, SP: Instituto Langage.

Olivier, D. (2013). La prise en compte de l'inconscient dans un lieu d'accueil de toutpetit avec ses parents. In Grandt-Gauliard, \& R. Turcanu (Orgs.), Freud s'invite dans les lieux d'accueil parents-enfants. Paris: Editions Érès.

Rouvray, C. (2013). Une pratique d'accueil parents-enfants, le cadre. In Grandt-Gauliard, \& R. Turcanu (Orgs.), Freud s'invite dans les lieux d'accueil parents-enfants. Paris: Editions Érès.

Teperman, D. W. (2005). Clínica psicanalítica com bebês: uma intervenção a tempo. São Paulo, SP: Casa do Psicólogo, Fapesp.

Vanier, A. (2011). Introduction: une singulière amnésie. In S. Freud (1905-1924). Trois essais sur la théorie sexuelle (pp. 9-72). Paris: Flammarion, Champs Classiques.

\section{Resumos}

(The position of psychoanalysts in a welcoming place for young children and their parents: from symbolic support to subjective constitution)

Based on examination of the specificities of psychoanalytic clinics for babies, this paper discusses the position of psychoanalysts in a welcoming place for young children and their parents. It concludes that the latter operates through symbolic support to maternity, and proposes a twist referring to the notion of prevention - seeing it as monitoring that participates in the process of babies' psychic constitution.

Key words: Psychoanalysis with babies, welcoming place, the position of psychoanalysts, psychic constitution

(La position du psychanalyste dans un lieu d'accueil enfants-parents: du support symbolique à la constitution subjective)

A partir d'un questionnement sur les spécificités de la clinique psychanalytique avec des bébés, cet article traite de la position du psychanalyste dans un lieu d'accueil enfants-parents. Il conclut que celui-ci opère à travers le support symbolique de la fonction maternelle et propose une torsion de la notion de prévention, conçue comme l'accompagnement qui participe à la mise en place du processus de constitution psychique du bébé.

Mots clés: Psychanalyse avec des bébés, lieu d'accueil enfants-parents, position du psychanalyste, constitution psychique 
(La postura del psicoanalista en un espacio de acogida para niños pequeños y sus padres: de la sustentación simbólica a la constitución subjetiva)

A partir de un cuestionamiento acerca de las especificidades de la clínica psicoanalítica con bebés, este artículo discute la postura del psicoanalista en un espacio de acogida para niños pequeños y sus padres. Se concluye que el psicoanalista actúa a través de la sustentación simbólica de la función materna y propone un giro con respecto al concepto de la prevención, concibiéndola como el seguimiento que participa en la instauración del proceso de constitución psíquica del bebé.

Palabras clave: Psicoanálisis con bebés, espacio de acogida, posición del psicoanalista, constitución psíquica

(Die Stellung des Psychoanalytikers in einer Anlaufstelle für Kleinkinder und ihre Eltern: von der symbolischen Unterstützung zur subjektiven Konstitution)

Basierend auf der Erforschung der spezifischen Aspekte der psychoanalytischen Klinik mit Kleinkindern beschreibt dieser Artikel die Stellung des Psychoanalytikers in einer Anlaufstelle für Kleinkinder und ihre Eltern. Wir kommen zum Schluss, dass der Psychoanalytiker die mütterliche Funktion symbolisch unterstützt und schlagen vor, das Konzept der Prävention abzuändern und es als Begleitung zu verstehen, als Teil der Erstellung des Prozesses der psychischen Konstitution des Kleinkindes.

Schlüsselwörter: Psychoanalyse mit Kleinkindern. Anlaufstelle, Position des Psychoanalytikers, psychische Konstitution

Citação/Citation: Lunardelli-Jacintho, A. F., Kupfer, M. C. M., \& Vanier, A. (2017, dezembro). A posição do psicanalista em um espaço de acolhimento para pequenas crianças e seus pais: da sustentação simbólica à constituição subjetiva. Revista Latinoamericana de Psicopatologia Fundamental, 20(4), 673-685. http://dx.doi.org/10.1590/1415-4714.2017v20n4p673.4

Editores do artigo/Editors: Profa. Dra. Ana Maria Rudge e Profa. Dra. Sonia Leite.

Recebido/Received: 13.4.2017/ 4.12.2017 Aceito/Accepted: 15.6.2017 / 6.15.2017 


\section{ARTIGOS}

Copyright: (C) 2009 Associação Universitária de Pesquisa em Psicopatologia Fundamental/ University Association for Research in Fundamental Psychopathology. Este é um artigo de livre acesso, que permite uso irrestrito, distribuição e reprodução em qualquer meio, desde que o autor e a fonte sejam citados / This is an open-access article, which permits unrestricted use, distribution, and reproduction in any medium, provided the original authors and sources are credited.

Financiamento/Funding: Os autores declaram não terem sido financiados ou apoiados. The authors have no support or funding funded to report.

Conflito de interesses/Conflict of interest: Os autores declaram que não há conflito de interesses / The authors have no conflict of interest to declare.

\section{Ana Francisca Lunardelli-Jacintho}

Psicóloga; Doutora em Psychopathologie et Psychanalyse/Psicologia pela Université Paris 7 - Diderot e pela Universidade de São Paulo - USP (São Paulo, SP, Br); Associação PREAUT, Paris.

217, rue de Tolbiac,

75013 Paris, France

analunardelli@gmail.com

\section{Maria Cristina Machado Kupfer}

Docente do Programa de Pós-Graduação em Psicologia Escolar e Desenvolvimento Humano, Universidade de São Paulo - USP (São Paulo, SP, Br); Membro fundador do Lugar de Vida - Centro de Educação Terapêutica (São Paulo, SP, Br).

R. Aramanaí, 335

05450-030 São Paulo, SP, Br.

mckupfer@usp.br

\section{Alain Vanier}

Docente; Diretor do laboratório Centre de Recherches Psychanalyse, Médecine et Société - CRPMS, Université Paris 7 - Diderot (Paris, França); Psicanalista.

14 bis, rue Raynouard

75016 Paris, Françe

alainvanier@noos.fr

This is an open-access article, which permits unrestricted use, distribution, 